\title{
Dynamic Effects on the Tropical Cloud Radiative Forcing and Radiation Budget
}

\author{
Jian Yuan, Dennis L. Hartmann, And Robert Wood \\ Department of Atmospheric Sciences, University of Washington, Seattle, Washington
}

(Manuscript received 22 January 2007, in final form 29 October 2007)

\begin{abstract}
Vertical velocity is used to isolate the effect of large-scale dynamics on the observed radiation budget and cloud properties in the tropics, using the methodology suggested by Bony et al. Cloud and radiation budget quantities in the tropics show well-defined responses to the large-scale vertical motion at $500 \mathrm{hPa}$. For the tropics as a whole, the ratio of shortwave to longwave cloud forcing (hereafter $N$ ) is about 1.2 in regions of upward motion, and increases to about 1.9 in regions of strong subsidence. If the analysis is restricted to oceanic regions with SST $>28^{\circ} \mathrm{C}, N$ does not increase as much for subsiding motions, because the stratocumulus regions are eliminated, and the net cloud forcing decreases linearly from about near zero for zero vertical velocity to about $-15 \mathrm{~W} \mathrm{~m}^{-2}$ for strongly subsiding motion. Increasingly negative cloud forcing with increasing upward motion is mostly related to an increasing abundance of high, thick clouds.

Although a consistent dynamical effect on the annual cycle of about $1 \mathrm{~W} \mathrm{~m}^{-2}$ can be identified, the effect of the probability density function (PDF) of the large-scale vertical velocity on long-term trends in the tropical mean radiation budget is very small compared to the observed variations. Observed tropical mean changes can be as large as $\pm 3 \mathrm{~W} \mathrm{~m}^{-2}$, while the dynamical components are generally smaller than $\pm 0.5 \mathrm{~W} \mathrm{~m}^{-2}$.

For relatively small regions in the east and west Pacific, changes in the relative magnitude of longwave and shortwave cloud forcing can be related to the PDF of vertical velocity. The east Pacific in 1987 and 1998 showed large reductions of $N$ in association with an increase in the fraction of the area in the domain with upward motion, and concomitant increases in high cloud. For the west Pacific in 1998, a large increase in $N$ was caused not so much by a change in the mean vertical motion, but rather by a shift from top- to bottom-heavy upward motion.
\end{abstract}

\section{Introduction}

Clouds play an important role in both energy and moisture budgets, and the impact of clouds on climate is a long-standing issue in atmospheric sciences. Data from the Earth Radiation Budget Experiment (ERBE) show that the net radiative effect of clouds on the earth's global mean radiation budget at the top of the atmosphere (TOA) is $\sim-20 \mathrm{~W} \mathrm{~m}^{-2}$. This results from roughly a $\sim 50 \mathrm{~W} \mathrm{~m}^{-2}$ increase of total reflected solar radiation (TRS) and a $\sim 30 \mathrm{~W} \mathrm{~m}^{-2}$ decrease of outgoing longwave radiation (OLR) when compared to clear skies (Ramanathan et al. 1989; Harrison et al. 1990). In the tropics $\left(30^{\circ} \mathrm{N}-30^{\circ} \mathrm{S}\right)$ clouds increase TRS by $45 \mathrm{~W} \mathrm{~m}^{-2}$ and reduce OLR by $33 \mathrm{~W} \mathrm{~m}^{-2}$, yielding a

Corresponding author address: Jian Yuan, Department of Atmospheric Sciences, University of Washington, Box 351640, Seattle, WA 98195.

E-mail: jiany@atmos.washington.edu total reduction in the net radiation of $12 \mathrm{~W} \mathrm{~m}^{-2}$, so that the effect of clouds on the tropical energy balance is less negative than on the global average, largely as a result of the presence of high, cold clouds in the tropics. The cloud effects on the radiative energy balance, which are often called cloud radiative forcing (CRF), may respond to external influences on the climate system and thereby constitute a substantial climate feedback (e.g., Schneider 1972; Cess et al. 1996). The tropical climate system response to an external perturbation is an important outstanding problem, and cloud feedback still stands as a large source of uncertainty in predicting future climate (Cess et al. 2001b; Stephens 2005; Solomon et al. 2007).

Clouds respond both to large-scale dynamical forcing and thermodynamic changes. Large-scale circulations can influence clouds, and the tropical radiation budget depends on both the amount and type of cloud present (Dhuria and Kyle 1990; Ockert-Bell and Hartmann 1992; Hartmann et al. 1992, 2001). Shifts or variations 
of large-scale circulation patterns can induce changes in local CRF (e.g., Hartmann and Michelsen 1993; Cess et al. 2001a; Allan et al. 2002). Thermodynamic changes in the tropics (e.g., changes in SST or atmospheric temperature and moisture profiles) could significantly affect cloud properties and hence constitute a climate feedback that produces a significant change in climate sensitivity (Ramanathan and Collins 1991; Hartmann et al. 2001; Lindzen et al. 2001; Larson and Hartmann 2003).

Because the large-scale atmospheric circulation in the tropics closely depends on the spatial distribution of SST, changes in tropical atmospheric circulation and cloudiness often reflect changes in SST pattern. Tropical mean SST variations, such as those associated with ENSO, are usually accompanied by changes in SST pattern. Total changes in cloud properties are not uniquely related to local SST, but also depend on the global pattern of SST. Hartmann and Michelsen (1993) showed that the effect of SST gradients and associated circulations can be minimized by averaging all quantities over the area of the dominant circulation patterns, such as the Hadley and Walker circulations in the tropics. Barsugli et al. (2006) showed that the sensitivity of climate models is dependent upon the structure of the tropical SST response to climate change.

Over regions of deep tropical convection the longwave cloud forcing (LWCF) and shortwave cloud forcing (SWCF) are both strong and nearly cancel each other so that the net cloud radiative effect (NetCRF) is nearly neutral and the ratio $N=-\mathrm{SWCF} / \mathrm{LWCF}$ is approximately equal to 1 (Kiehl and Ramanathan 1990). The parameter $N$ is a simple way to measure the relative size of the short- and longwave cloud forcing that is independent of the amount of cloud present or the absolute magnitude of the cloud forcing; $N=1$ indicates that short- and longwave cloud forcing are equal and opposite. Kiehl (1994) suggested that the near cancellation between LWCF and SWCF in the tropics is a coincidence, because deep, optically thick clouds near the tropopause perforce have long- and shortwave effects that approximately cancel. Hartmann et al. (2001) argued that deep convective clouds can have either strongly positive or negative effects on the radiation balance, depending on their optical depth, and that the cancellation is a property of the ensemble of clouds associated with deep convection in the tropics. They suggested that a feedback process between SST gradients and convection can drive the net radiation toward a nearly uniform value over expanses of nearly uniformly warm water. They further suggested that the need to keep the net radiation in the warm tropics approximately uniform in space would require a
NetCRF for convective clouds near $-10 \mathrm{~W} \mathrm{~m}^{-2}$, or $N \sim 1.2$.

Bony et al. (2004) proposed a framework for extracting the effect of mean vertical motion on the cloud fields by sorting the data into categories based on the vertical motion. In this study we use Bony et al.'s method to further investigate the observed relationship between cloud properties and large-scale vertical motion. We explore how much of regional and tropical mean variations in radiation budget quantities can be explained with changes in vertical motion. In particular, we will investigate whether changes in the probability density function (PDF) of vertical velocity can explain long-term changes in radiation budget quantities (Wong et al. 2006), and we will revisit changes in the regional values of the ratio of the shortwave to longwave cloud forcing $(N)$ in the tropical Pacific studies by Cess et al. (2001a,c) and Allan et al. (2002).

The data used in this study and more detailed information about Bony et al.'s method are introduced in section 2. In section 3 we examine the relationship of clouds and CRF in the tropics to large-scale vertical velocity. In section 4 , the annual and interannual variations of the dynamic effect on tropical mean longwave cloud forcing are examined. The variation of $N$ in fixed Pacific regions is investigated in section 5. Conclusions and a summary are in section 6 .

\section{Data and Bony et al.'s analysis method}

\section{a. Data}

The ERBE is the first multisatellite system designed to measure the earth's radiation budget. The 5-yr gridded monthly mean ERBE scanner data (Barkstrom 1984; Barkstrom and Smith 1986) and the latest 15-yr wide field-of-view (WFOV) nonscanner data (Wong et al. 2006) are used in this study. The scanner data are taken from the ERBE S-4G dataset produced by the ERBE Data Management Team and archived at the National Aeronautics and Space Administration (NASA) Langley Research Center's Earth Observing System Data and Information System (EOSDIS) Distributed Active Archive Center (EOSDIS Langley DAAC). Here, S-4G contains gridded data of time and space averages of all the individual estimates of radiant flux at the TOA for 1 month and one spacecraft or a combination of spacecraft for both scanner and nonscanner. The clear-sky flux and albedo based on the ERBE scene identification method (Barkstrom and Smith 1986; Taylor and Stowe 1984) are also provided in S-4G. The nonscanner data (ERBE S10N WFOV ERBS Edition3_Rev1) are the latest reprocessed ERBE Earth Radiation Budget Satellite (ERBS) scan- 
ner-independent WFOV nonscanner monthly mean product officially released at Langley DAAC with a user-applied revision adjustment (Wong et al. 2006).

The Clouds and the Earth's Radiant Energy System (CERES) Tropical Rainfall Measuring Mission (TRMM; 1998) and CERES Terra (2001-02) ERBElike gridded TOA radiant fluxes are also used in this study. CERES (Wielicki et al. 1996) is a key component of the EOS program. The CERES project has provided a continuation of the ERBE record with the CERES ERBE-like product using data from the TRMM, Terra, and Aqua spacecraft (Doelling et al. 2006). International Satellite Cloud Climatology Project (ISCCP) data during 1983-2001 are also used in this study (Rossow and Schiffer 1999).

Three different reanalysis products are used here to characterize the vertical velocity field. The 40-yr European Centre for Medium-Range Weather Forecasts (ECMWF) Re-Analysis (ERA-40) project is a comprehensive global analysis for the 45-yr period covering September 1957-August 2002 (Uppala et al. 2005). The National Centers for Environmental Prediction (NCEP) and National Center for Atmospheric Research (NCAR) have cooperated to produce a retroactive reanalysis of more than 50 yr (1948-present) of global analysis of atmospheric fields (NCEP-NCAR reanalysis) in support of the needs of the research and climate monitoring communities (Kalnay et al. 1996; Kistler et al. 2001). The NCEP-Department of Energy (DOE) Atmospheric Model Intercomparison Project (AMIP-II; hereafter NCEP-DOE) reanalysis is an updated version of the NCEP-NCAR reanalysis, with some significant improvements (Kanamitsu et al. 2002). We use 500-hPa-level $\omega_{500}$ data as in Bony et al. (2004) and also use the principal components of the vertical distribution of omega to better characterize the vertical velocity at all levels. The major results in this study are the same for the three reanalysis datasets, so we will mostly only present results obtained with the ERA-40 data. The extended reconstructed sea surface temperature (ERSST) data (Smith and Reynolds 2004) are also used in this study.

All data used here are monthly means. The $\omega_{500}$ data from three reanalyses, the satellite data from the ERBE scanner (hereafter ERBE) data, and CERES ERBElike (hereafter CERES) data are gridded at $2.5^{\circ}$ resolution. The OLR and TRS from ERBS nonscanner (hereafter ERBS_WOV) data are gridded at $5^{\circ}$ resolution.

\section{b. Bony et al.'s analysis}

Bony et al.'s (2004) analysis is a methodology to attempt to separate the dynamic and thermodynamic effects on cloud and radiation changes in either obser- vations or models. It discretizes the large-scale tropical circulation into a set of dynamic regimes defined by values of the monthly mean $500-\mathrm{hPa}$ pressure velocity $\omega_{500}$. For each dynamical regime the mean of the variables of choice (usually the cloud or radiation budget variables) are derived from observations or reanalyses. Temporal variations in the tropics-wide mean of any climatologically relevant variable can then be expressed as the sum of a component arising from temporal variations in the PDF of omega (the so-called dynamic component) and the remaining variations about the mean value of the variable in each dynamical regime (the thermodynamic component).

Following Bony et al. (2004), $\bar{P}_{\omega}$ is the PDF of midtroposphere vertical velocity and $\bar{P}_{\omega} d \omega$ is the mean statistical weight associated with vertical velocities in the range from $\omega$ to $(\omega+d \omega)$ over the sample of interest, in this case the total area of the tropics during the time period of interest. The mean value of a particular variable $C$ in a dynamical regime is defined as $\bar{C}_{\omega}=\Sigma \sigma_{\omega \mathrm{i}} C_{\omega \mathrm{i}} / \Sigma \sigma_{\omega \mathrm{i}}$, where $i$ refers to an individual region with vertical velocity between $\omega$ and $\omega+d \omega$ in the tropics; $\sigma_{\omega \mathrm{i}}$ is the area of this region, $C_{\omega \mathrm{i}}$ is the value of $C$ in this region, and the sum is taken over all the regions within the domain for which the vertical velocity lies in the interval $\omega \sim(\omega+d \omega)$. Once the means for each dynamical regime are computed, the mean value of $C$ in the domain of interest can be expressed as an integral over the dynamical regimes as

$$
\bar{C}=\int_{-\infty}^{\infty} \bar{P}_{\omega} \bar{C}_{\omega} d \omega
$$

where $\bar{P}_{\omega}$ and $\bar{C}_{\omega}$ can be derived based on a climatological mean state (e.g., 5-yr mean of 1985-89). For a specified period or subdomain, the $P_{\omega}$ and $C_{\omega}$ can be considered as the mean values plus small perturbations $\delta P_{\omega}$ and $\delta C_{\omega}$. Then, the total perturbation (climate change) of tropical mean of $C$ is

$$
\begin{aligned}
\delta C= & \int_{-\infty}^{\infty} \delta P_{\omega} \bar{C}_{\omega} d \omega+\int_{-\infty}^{\infty} \bar{P}_{\omega} \delta C_{\omega} d \omega \\
& +\int_{-\infty}^{\infty} \delta P_{\omega} \delta C_{\omega} d \omega .
\end{aligned}
$$

The three terms on the right-hand side of (2) can be called the dynamic component, the thermodynamic component, and the covariance, respectively.

LWCF, SWCF, and NetCRF are defined as

$$
\begin{aligned}
\text { LWCF } & =\text { OLRcs }- \text { OLR, } \\
\text { SWCF } & =\text { TRScs }- \text { TRS, } \\
\text { NetCRF } & =\text { LWCF }+ \text { SWCF, }
\end{aligned}
$$



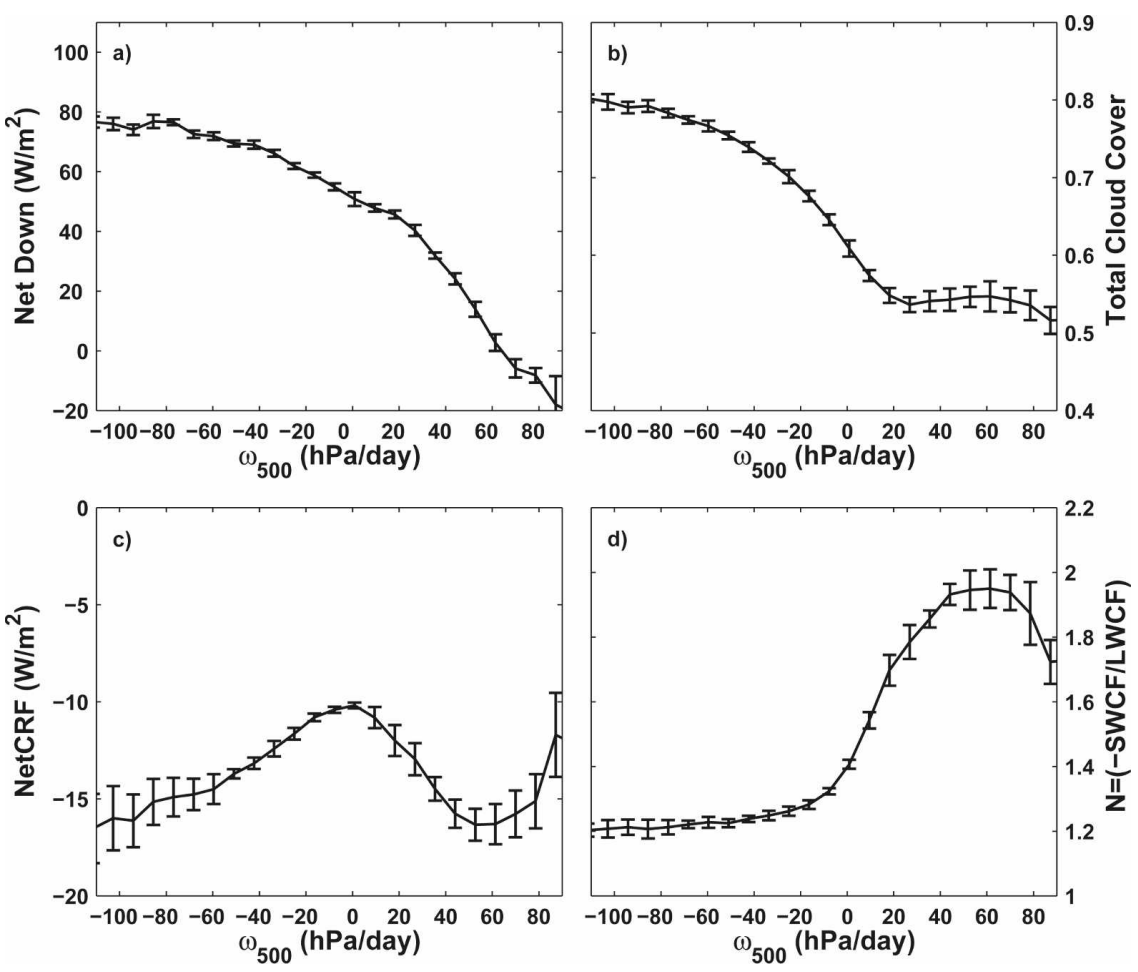

FIG. 1. Clouds and their radiative properties composited with respect to $\omega_{500}$. The error bars show the standard deviation of the 48 12-month running mean relations.

where TRS indicates the total reflected solar radiation and the subscript "cs" refers the same physical variable estimated for clear-sky conditions. The annual cycle will have an obvious effect on the insolation at any location, so to reduce the influence of the annual cycle on the shortwave budget we consider 12-month running mean values in most of this study. In section $3 \mathrm{~b}$ we will specifically look at the effect of large-scale circulation on the annual variation of cloud longwave forcing.

\section{Relationships of clouds and CRF in the tropics to large-scale vertical velocity}

Figure 1 shows some radiation budget and cloud properties in the tropics $\left(30^{\circ} \mathrm{N}-30^{\circ} \mathrm{S}\right)$ as a function of $\omega_{500}$. A total of forty-eight 12-month (1985-89) running mean relations for ERBE variables have been derived for each $2.5^{\circ} \times 2.5^{\circ}$ region using ERA-40 vertical velocities. The 48 examples are then averaged to get the climatological mean relations with the annual cycle removed (solid lines). Bar lines in Fig. 1 show the standard deviation of the 48 annual mean relations, and indicate how stable the averages are from one 12-month period to the next.

Figure 1a shows the net incoming radiation as a function of $\omega_{500}$. For the strongest upward velocities the net radiation is about $80 \mathrm{~W} \mathrm{~m}^{-2}$, and these regions correspond to the regions of warm SST. For strongly downward vertical velocities, the net radiation is near zero. The strongly downward motion composite contains contributions from the poleward margins of the tropical band and the stratocumulus regimes of the tropics that occur in the eastern oceans and over Southeast Asia. Figure $1 \mathrm{~b}$ shows the ISCCP cloud cover as a function of dynamical regime. For strongly upward vertical velocities the cloud cover averages $80 \%$, while for downward mean motions it is about $55 \%$.

Figures $1 \mathrm{c}, \mathrm{d}$ show the NetCRF and the ratio $N=$ $-\mathrm{SWCF} / \mathrm{LWCF}$. The NetCRF is only weakly dependent on the vertical velocity regime, and ranges from -10 to $-17 \mathrm{~W} \mathrm{~m}^{-2}$. The observed annual mean NetCRF ranges from $-50 \mathrm{~W} \mathrm{~m}^{-2}$ over the coastal stratocumulus regions to near zero near regions of deep convection (e.g., Klein and Hartmann 1993). The small value of about $-17 \mathrm{~W} \mathrm{~m}^{-2}$ for strongly subsiding regions indicates that a mixture of cold SST stratocumulus regions and warmer subsiding regions with weaker cloud forcing has gone into the strongly subsiding composites. These regions have similar subsiding motions, but very different SST and cloud conditions. The value of $N$ for rising motion is nearly constant at about 1.2, which is characteristic of deep convective, high SST regions in the tropics. As vertical motions become 

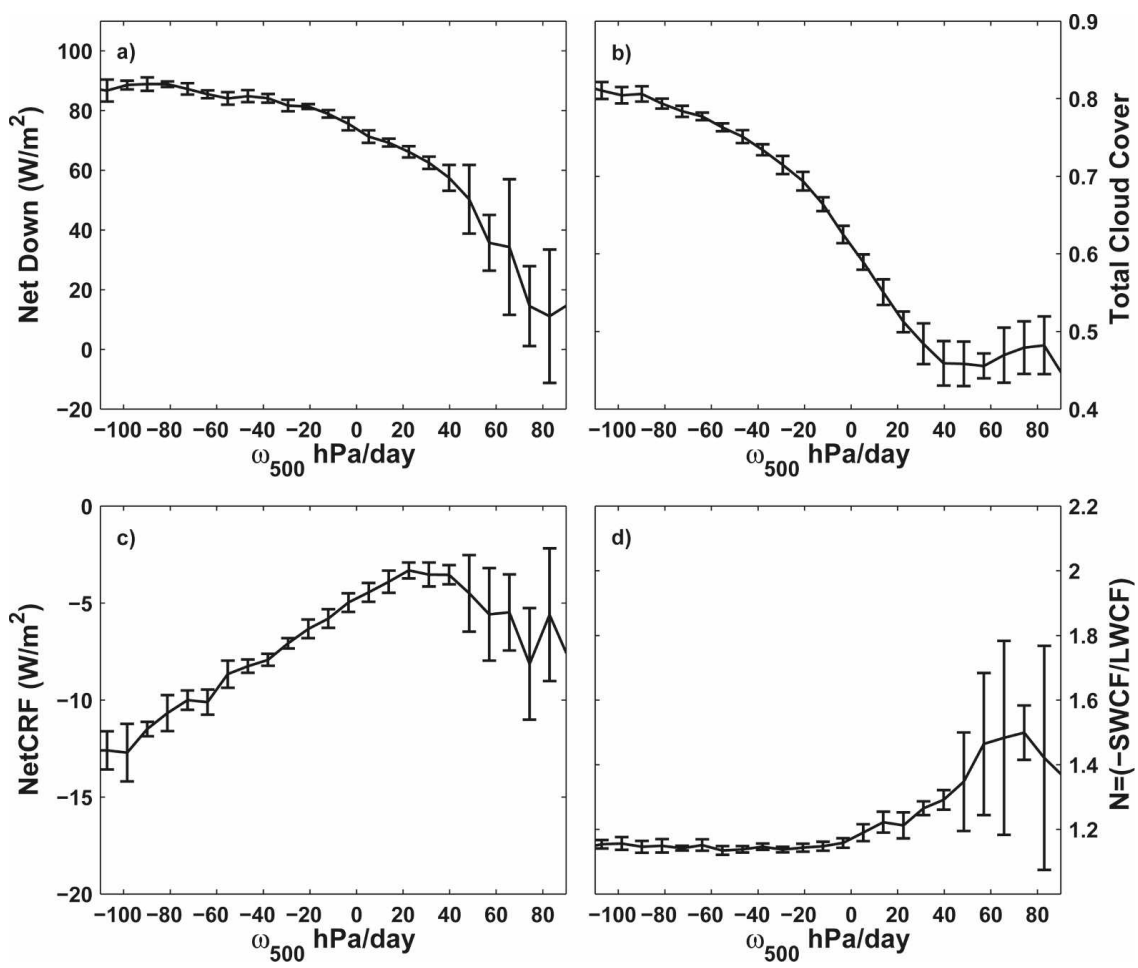

FIG. 2. Same as Fig. 1, but for regions where the SST $>28^{\circ} \mathrm{C}$.

downward, $N$ rises to a value near 2.0 , which again is a mixture of stratocumulus regimes, which have $N \sim 4$, and trade cumulus regions where $N \sim 1$. One limitation of the Bony et al. method is that the dynamical regimes can often include very different climate and cloud regimes, and thus give an average sensitivity to vertical motion that may be weaker or stronger than the sensitivity in specific climate regimes. We explore this next by constraining the region of interest to the warm-pool region.

Figure 2 is like Fig. 1, except that the domain of interest has been restricted to oceanic areas where the SST is greater than $28^{\circ} \mathrm{C}$. In this case the net cloud radiative forcing is a nearly linear function of vertical motion, decreasing from about $-3 \mathrm{~W} \mathrm{~m}^{-2}$ at downward motion of $40 \mathrm{hPa}$ day $^{-1}$ to about $-13 \mathrm{~W} \mathrm{~m}^{-2}$ at $-110 \mathrm{hPa}$ day $^{-1}$. The ratio $N$ stays very constant near 1.2 for vertical velocities from 0 to $-110 \mathrm{hPa}$ day $^{-1}$. This very constant value of $N$ and its relation to cloud properties is explored further using ISCCP data.

Figure 3 is a diagram of the ISCCP cloud categories as grouped together here following Ockert-Bell and Hartmann (1992), but modified to divide thin and thick, high cloud at an optical depth of 3.6, close to the value of 4 chosen by Kubar et al. (2007, hereafter KHW), to separate clouds with positive and negative effects on the net radiation. Figure 4 shows the fractional coverage of these ISCCP cloud categories as a function of vertical motion for both the whole tropics $\left(30^{\circ} \mathrm{N}-30^{\circ} \mathrm{S}\right)$ and the warm pool $\left(\mathrm{SST}>28^{\circ} \mathrm{C}\right)$. High, thin clouds remain relatively constant as the vertical velocity increases from weakly to strongly upward values. As expected, high, thick clouds increase with upward vertical velocity, because they are more closely related to pre-

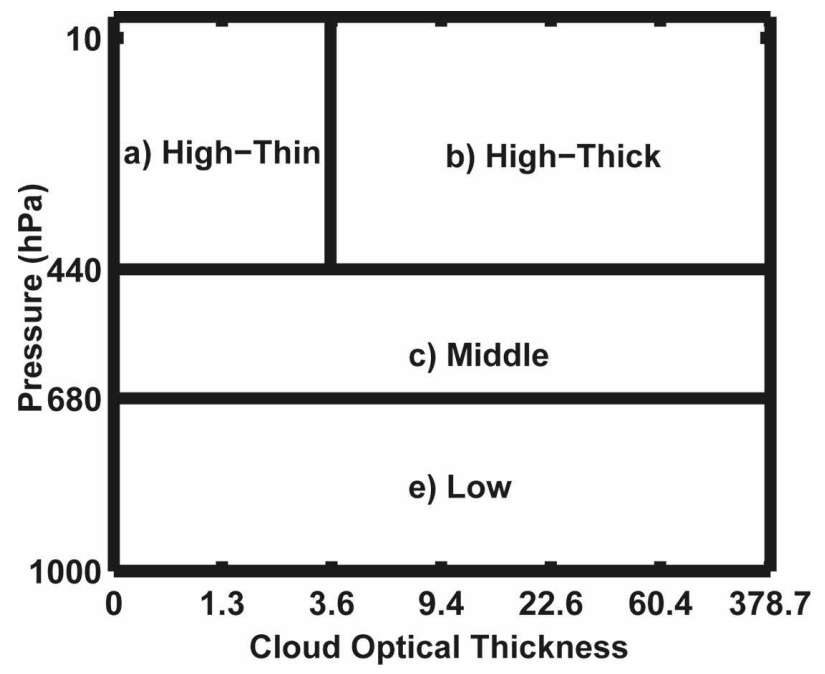

FIG. 3. ISCCP cloud classes used in the analysis. 


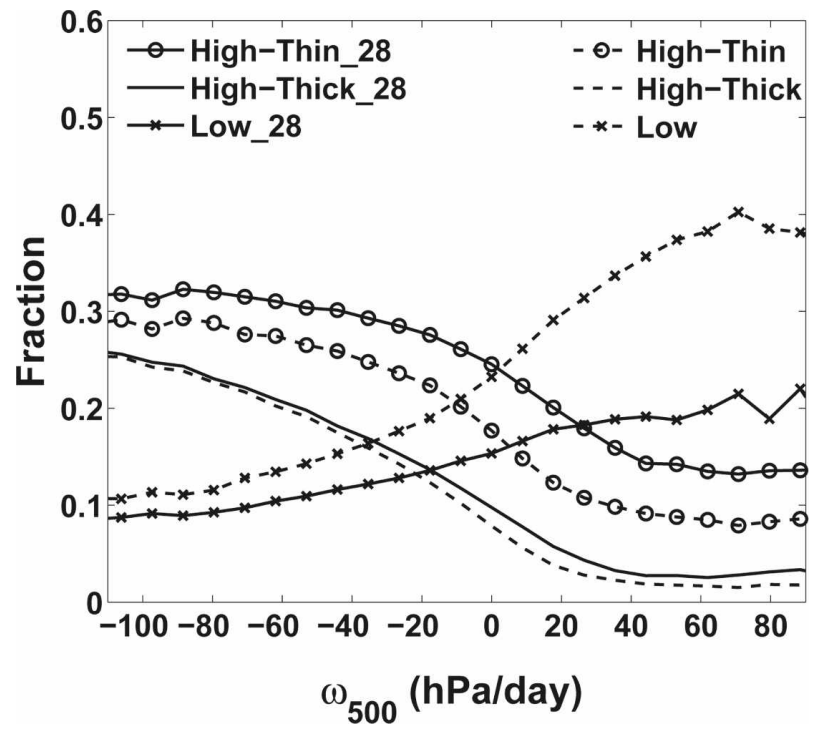

FIG. 4. ISCCP cloud classes composited as in Figs. 1 and 2.

cipitation (KHW), but the increase in high, thick clouds is compensated to some extent by a decrease in low clouds. Middle clouds occupy about $15 \%$ of the area, but their abundance is also almost independent of the magnitude of the upward velocity (not shown). The result is a very weak sensitivity of $N$ to the magnitude of the upward motion, as shown in Fig. 2.

Figure 5 shows that the increasingly negative NetCRF as the vertical velocity increases (shown Fig. 2c) is most closely associated with an increase in the high, thick cloud type, which has a negative effect on the energy balance (Hartmann et al. 2001). To construct the data in Fig. 5 we take the cloud forcings computed for the 42 ISCCP categories used in Hartmann et al. (2001) and multiply them by their ISCCP cloud abundances at different values of the vertical velocity. These are then aggregated to produce the curves in Fig. 5. We also computed the cloud forcing using the ISCCP net cloud forcings from Zhang et al. (2004), and the results were essentially identical to the calculations shown in Fig. 5. The SWCF is more strongly negative in this ISCCP reconstruction than in the ERBE data, but the slope of the NetCRF curve in Fig. 5 is very similar to that in Fig. 2c. This slope results from the increasing abundance of high, thick cloud (called anvil cloud in KHW) with increasingly strong upward motion. The sensitivity of SWCF to vertical velocity is almost entirely explained by the high, thick cloud abundance.

The SST increases steadily from about $28.8^{\circ}$ to $29.2^{\circ} \mathrm{C}$ as the vertical motion goes from 0 to $-110 \mathrm{hPa}$ day $^{-1}$ in the warm pool (not shown), so the cloud radiative forcing in the warm-pool region (Fig. 2a) is most

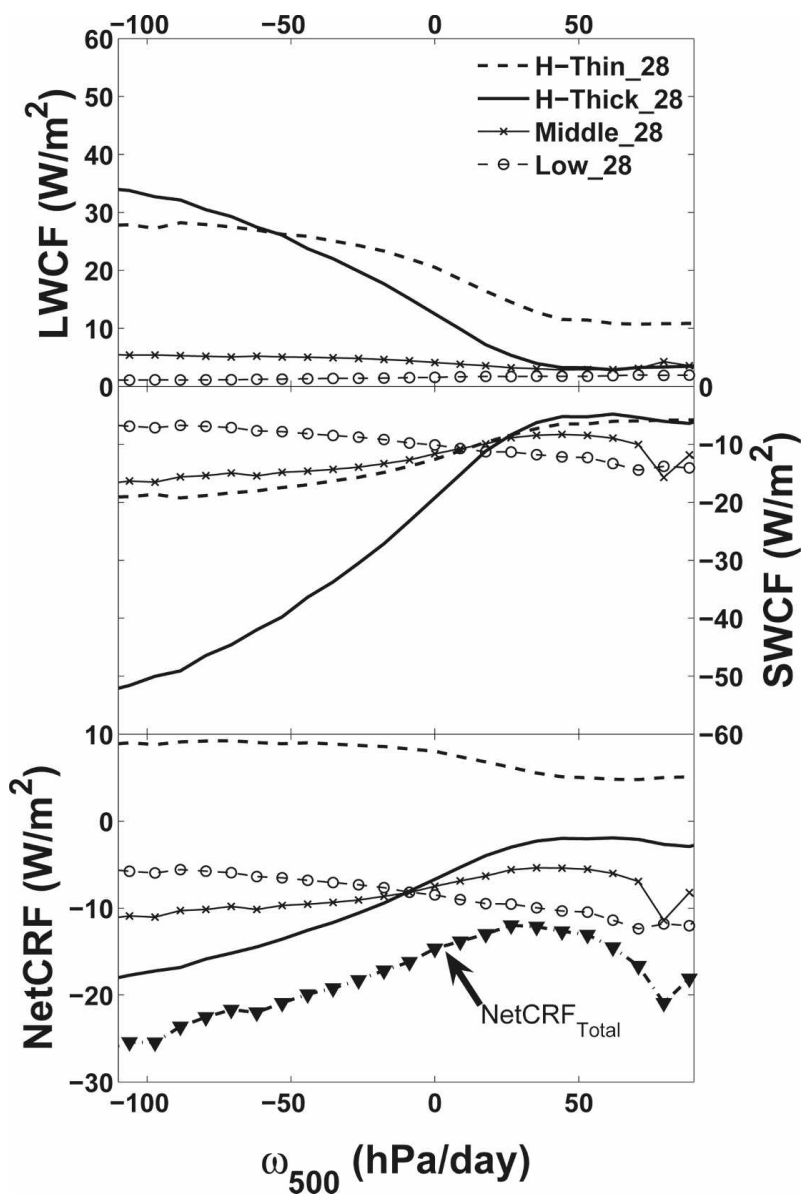

FIG. 5. ISCCP-derived CRF contributions for the SST $>28^{\circ} \mathrm{C}$ domain.

strongly negative where the SST is greatest and the mean motion is most upward. These observations are consistent with the idea that high SST leads to intense convection and upward motion, which leads to more strongly negative cloud radiative forcing. This feedback tends to both flatten SST gradients in the warm-pool region (Ramanathan and Collins 1991) and drive the net radiation toward a uniform value in the warm-pool region (Hartmann et al. 2001). The net radiation still increases with increasing upward motion because the greenhouse effect increases by about $70 \mathrm{~W} \mathrm{~m}^{-2}$ as vertical velocity goes from 0 to $-120 \mathrm{hPa}$ day $^{-1}$. About 20 $\mathrm{W} \mathrm{m} \mathrm{m}^{-2}$ of this $70 \mathrm{~W} \mathrm{~m}^{-2}$ is contributed by water vapor greenhouse effects and $50 \mathrm{~W} \mathrm{~m}^{-2}$ is from clouds (Fig. 5 shows the cloud contribution). The fractional cloud cover increases from about $45 \%$ for strongly downward mean motion $\left(+40 \mathrm{hPa}\right.$ day $\left.^{-1}\right)$ to about $80 \%$ for strongly upward mean motion $\left(-110 \mathrm{hPa} \mathrm{day}^{-1}\right)$ (Fig. $2 \mathrm{~b})$. The relative contributions to this $35 \%$ change are high, thin $(+20 \%)$; high, thick $(+21 \%)$; middle, thick $(+5 \%)$; and low clouds $(-11 \%)$. 


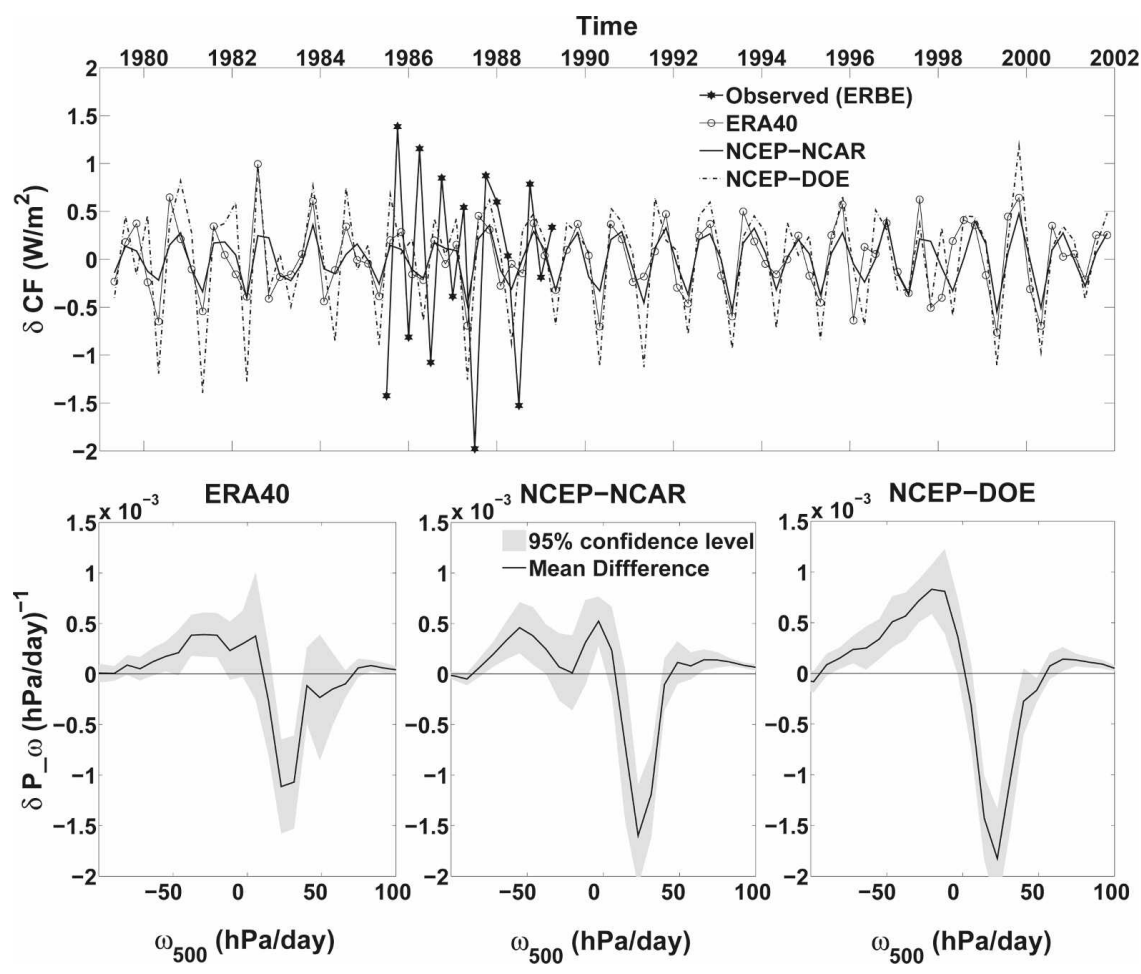

FIG. 6. (top) Annual variations of dynamic components. (bottom) The differences between PDFs of DJF and JJA. Gray areas show $95 \%$ confidence intervals.

\section{Temporal changes in tropical mean cloud forcing}

\section{a. The annual cycle in tropical mean dynamics}

The tropical large-scale circulation closely depends on SST patterns because changes in large-scale circulation often occur in association with modifications of the spatial distribution of SST (Lindzen and Nigam 1987; Hartmann and Michelsen 1993). Current climate models also show that patterns of large-scale circulation follow SST patterns well (Allan et al. 2002) and even suggest that the global sensitivity of climate models depends on the structure of the tropical SST response (Barsugli et al. 2006). The strongest regular cycle in SST distribution is the annual cycle, so in this section we examine the ability of the Bony et al. (2004) method to capture dynamically driven variations associated with the annual cycle.

Figure 6 shows the annual variations of the dynamic component of tropical mean LWCF. To compute the values in Fig. 8, the PDFs of $\omega_{500}$ for each month during 1979-2001 were derived from reanalyses. These PDFs were then projected onto the mean relation to LWCF from the 1985-89 period (e.g., Fig. 1) to get the tropical mean LWCF anomalies associated with variations in the PDF (the dynamical component). For each year the annual mean is removed and the monthly values are grouped into four seasons [December-February (DJF), March-May (MAM), June-August (JJA), and September-November (SON)], so that the time interval in the upper panel of Fig. 6 is 3 months. The seasonal departures of the means of topical mean LWCF from the ERBE dataset are also plotted in Fig. 6.

To test the sensitivity of these estimates to the reanalysis products we analyze the three reanalysis products separately. The dynamic components estimated from different reanalyses all have clear annual fluctuations. The amplitudes are slightly different but their temporal behavior is similar. The largest peak-to-peak amplitude of the annual variation is about $1.5 \mathrm{~W} \mathrm{~m}^{-2}$ for the NCEP-DOE reanalysis. The ERBE data show a corresponding amplitude of about $2-3 \mathrm{~W} \mathrm{~m}^{-2}$, which is not all associated with the annual cycle. Each reanalysis product shows a maximum positive dynamical contribution to LWCF anomalies around DJF or SON and a minimum in JJA.

The differences between PDFs of DJF and JJA are shown in the lower panel of Fig. 6. The difference of the PDF between two seasons is calculated for each year to generate a sample of differences, from which confidence limits can be determined. The PDFs of $\omega_{500}$ derived from the three reanalyses show consistent responses to the annual cycle. All of the reanalyses show an increase in the coverage of ascending areas in DJF 

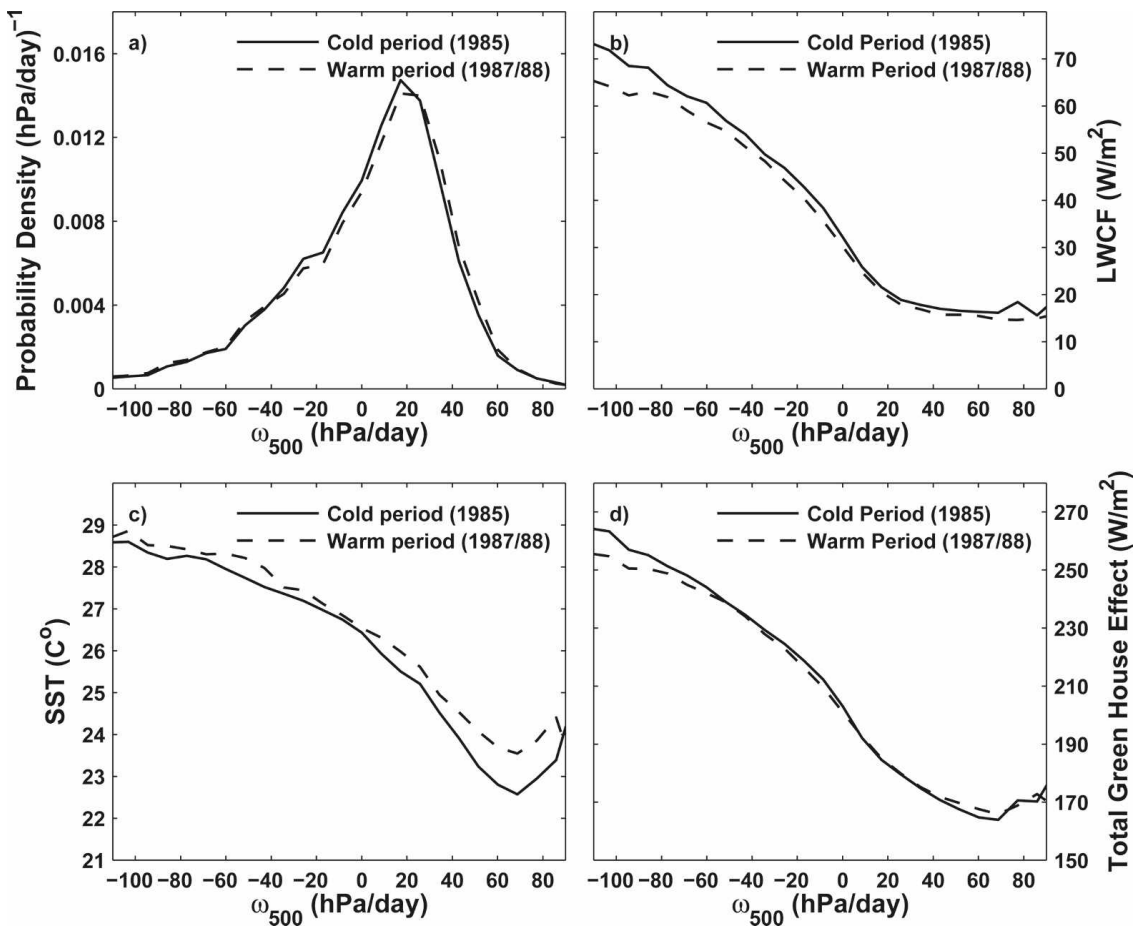

FIG. 7. Bony et al. (2004) diagrams, showing the data for the warmest and coldest years.

relative to JJA significant at the $95 \%$ level. It is not clear why DJF has more upward motion, but it may have to do with the Asian summer monsoon bringing intense convection to relatively higher latitudes.

\section{b. The effect of ENSO}

Tropical cold and warm El Niño-Southern Oscillation (ENSO) events include significant changes in both the spatial distribution and the mean value of tropical SST. To try to isolate effects of SST on tropical mean climate, we compare the 12-month period with the highest tropical mean $\left(30^{\circ} \mathrm{N}-30^{\circ} \mathrm{S}\right) \mathrm{SST}$ with the period with the lowest tropical SST. Figure 7 compares Bony et al. (2004) diagrams during the warmest period (1987/ 88 , with the annual tropical mean SST of $26.1^{\circ} \mathrm{C}$ ) with those during the coldest period (1985, with the annual tropical mean SST of $25.8^{\circ} \mathrm{C}$ ). Figure 7 a shows that the PDF of $\omega_{500}$ shifts slightly toward more subsidence during the warmest 12-month period compared to the coldest. LWCF decreases slightly, especially for strong rising motion (Fig. 7b), but the total greenhouse effect, $G=\sigma T^{4}-$ OLR, does not change very much between the $2 \mathrm{yr}$ (Fig. 7d). A decreasing LWCF with constant $G$ suggests that the clear-sky greenhouse effect has increased while the cloud effect has decreased or remained constant. An increase in the greenhouse effect with warmer SST is consistent with water vapor feedback. The distribution of SST with vertical velocity in Fig. 7c suggests, as expected, that the strongest upward motions occur over the warmest SST. The total greenhouse effect increases from about $170 \mathrm{~W} \mathrm{~m}^{-2}$ in the subsiding regions with cooler SST, to about $260 \mathrm{~W} \mathrm{~m}^{-2}$ in the warm regions with strongly upward vertical velocities. Figure $7 \mathrm{~b}$ suggests that clouds contribute about $50 \mathrm{~W} \mathrm{~m}^{-2}$ of this $90 \mathrm{~W} \mathrm{~m}^{-2}$ change in greenhouse effect for the tropical average.

The dynamical effects expressed in Figs. 1 and 7 for the entire tropics are not very effective in explaining the changes in tropical mean radiation budget quantities that are observed, because only modest changes in the PDF of vertical velocity are observed. To illustrate this we use the data in Fig. 7 to compute the dynamical component of change using (2). Comparisons between dynamic effects and thermodynamic changes of annual tropical mean LWCF and SWCF during 1985-89 are shown in Fig. 8. The thermodynamic component is simply the residual that is left when the dynamic component is subtracted from the observed change. Figure 8 shows that the interannual variation of the dynamic component is much smaller than the observed changes. The fluctuations of thermodynamic components are $\sim 2.5$ and $\sim 1.5 \mathrm{~W} \mathrm{~m}^{-2}$ for LWCF and SWCF, while the dynamic components vary by $\sim 0.3$ and $\sim 0.2 \mathrm{~W} \mathrm{~m}^{-2}$, respectively. 

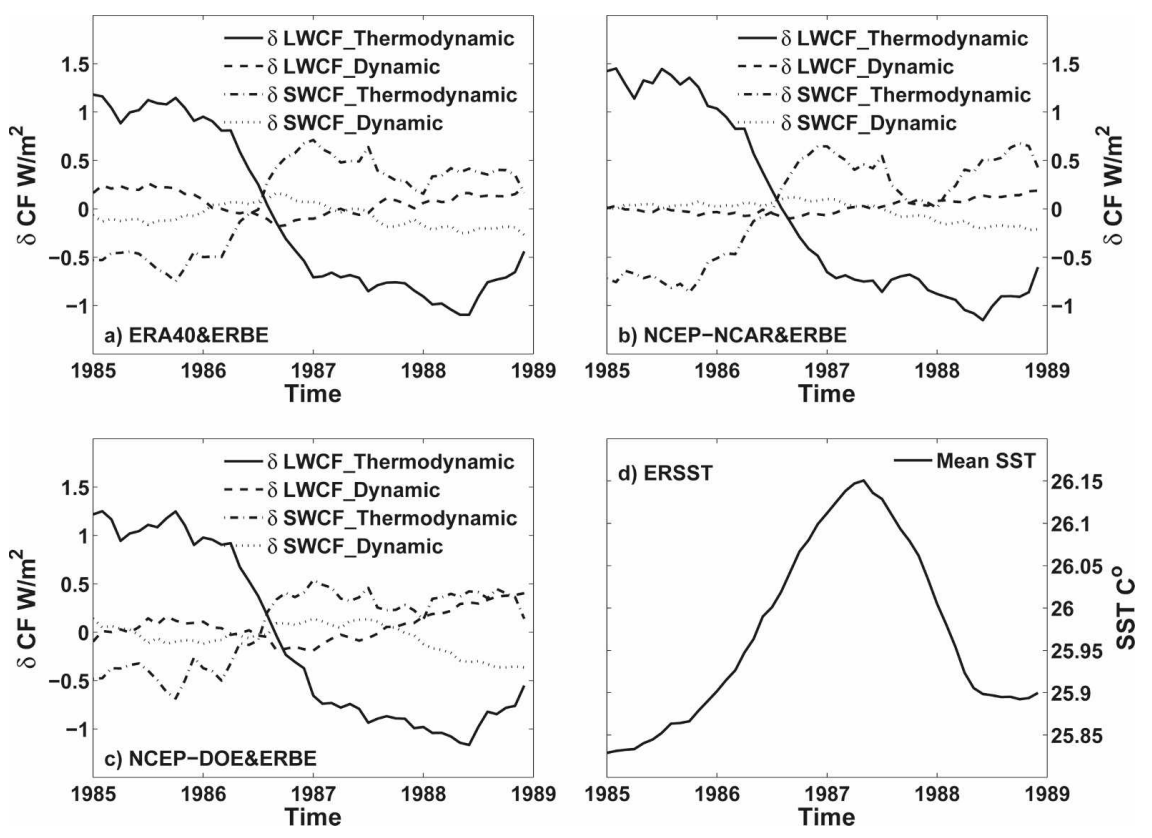

FIG. 8. Comparisons between dynamic and thermodynamic components of cloud forcing during 1985-89.

\section{c. Interannual variations}

Wielicki et al. (2002) compiled data from the last two decades of satellite measurements of radiative fluxes from both the ERBE and CERES instruments. They found that the tropical mean $\left(20^{\circ} \mathrm{N}-20^{\circ} \mathrm{S}\right)$ earth radiation budget showed significant changes between the late 1980s and the 1990s. More recently, Wong et al. (2006) have described a new version of ERBS_WOV data in which some corrections for satellite altitude and shortwave sensor dome have been applied. The new data show trends in TOA OLR, TRS, and net radiation of $0.7,-2.1$, and $1.4 \mathrm{~W} \mathrm{~m}^{-2}$, respectively.

Chen et al. (2002) concluded that the trends shown in Wielicki et al. (2002) are due to a strengthening of the tropical atmospheric circulation and suggested that an increase in circulation strength could explain the trend in tropical mean radiative fluxes. Clement and Soden (2005) investigated this possibility by applying Bony et al.'s (2004) method to results produced by climate models. Their models suggested that at least a doubling of the circulation strength is required to alter the TOA energy balance to observed magnitudes. In this section we use reanalysis data to consider whether dynamical regime shifts can explain observed variations in the tropical mean energy budget through time, and conclude that shifts in the PDF of vertical velocity are too small to affect very much. We use the same method as we used for the annual cycle, in which the vertical velocity sensitivities of the ERBE period were projected onto the long-term variability of the vertical velocity PDF from the reanalysis data over the $45 \mathrm{yr}$ of the ERA-40 data.

The results for the 1979-2001 period of WFOV data are similar to those shown in Fig. 7 for the 1985-89 period. The changes in the tropical mean vertical velocity PDF, when projected onto the radiation budget sensitivities as in Figs. 1 and 5, produce rather modest effects compared to the observed changes. We conclude that if changes in the large-scale vertical motion field are responsible for the long-term changes in the Wong et al. (2006) dataset, then this effect is not captured by the tropical mean PDF of vertical velocity. This result is consistent with the model analysis of Clement and Soden (2005).

\section{Regional and temporal differences in cloud forcing}

We now turn to the question of interannual variations in $N(-\mathrm{SWCR} / \mathrm{LWCR})$ in restricted regions of the tropical east and west Pacific. Cess et al. (2001a) compared the $N$ in fixed geographical areas [west Pacific: $10^{\circ} \mathrm{N}-5^{\circ} \mathrm{S}, 100^{\circ}-170^{\circ} \mathrm{E}$ (WP), and east Pacific: $7.5^{\circ} \mathrm{N}-$ $\left.7.5^{\circ} \mathrm{S}, 200^{\circ}-280^{\circ} \mathrm{E}(\mathrm{EP})\right]$ in the tropical Pacific using 4-months of broadband radiation budget data for each year from ERBE (1985-90) and CERES (1998). They found that the $N$ increased to $\sim 1.6$ in the west Pacific warm pool in 1998. In the east Pacific regions $N$ is found 
to be anomalously low in 1987 and 1998 compared to other years during the ERBE period. In a later paper Cess et al. (2001c) reevaluated $N$ using the available 8 -month record in a smaller area in the west Pacific that is more uniformly convective, and found the $N$ is reduced to 1.25 , much closer to the value that seems characteristic of the warm pool during the ERBE period (Fig. 2). The effect is much larger in the first 4 months of 1998 than in May through August.

Allan et al. (2002) found that in regions with strongly rising motions $\left(\omega_{500}<-60 \mathrm{hPa}\right.$ day $^{-1}$, based on NCEP-NCAR reanalysis), the anomalous value of the area mean of $N$ is partly due to the incursion of descending air in that area during the 1998 El Niño and partly due to longer-period climate changes that are not explained. Lu et al. (2004) hypothesized that the change in 1998 was due to a collapse in the Walker circulation and demonstrated that a Walker circulation collapse did occur in a GCM in response to the observed SST changes; however, they did not explore the dependence of the cloud properties on the vertical velocity. These studies suggest that the compositing $N$ in a dynamical framework (e.g., $\omega_{500}$ ) can help separate the effect of shifts in the large-scale circulation from other factors.

We next test whether the changes in large-scale vertical velocity can explain the changes in cloud forcing in the EP and WP regions. To simplify the analysis, the EP and WP regions are divided into areas with ascending and descending motions. Figures 1,2, and 5 suggest that the largest changes of $N$ occur as the vertical velocity passes through zero, so that a simple binary decomposition is a good approximation. The analysis has also been done using the complete PDF of vertical motion, but the results are very similar to those shown below. The year 1985 is chosen to be the reference year. Eight months (January-August) of monthly mean data for each year are used, because only those months are available for 1998. Cloud forcing data are obtained from ERBE and CERES. The vertical motion fields are from ERA-40, but the NCEP-NCAR and NCEP-DOE reanalyses give similar results. Error bars indicate $95 \%$ confidence limits, which take into account the spatial and temporal autocorrelation to compute the actual number of degrees of freedom.

The top panel of Fig. 9 shows the fraction of the domain covered by ascending and descending motions in the EP region. In 1987 and 1998 much more ascending motion occurs than in other years. The middle panel of Fig. 9 shows the values of $N$ for the ascending and descending regions in each year. In the descending regions the values range from about 2.0 to 2.6 , while in ascending regions they range from 1.4 to 1.7. The lower panel shows the changes of $N$ with respect to 1985 ob-

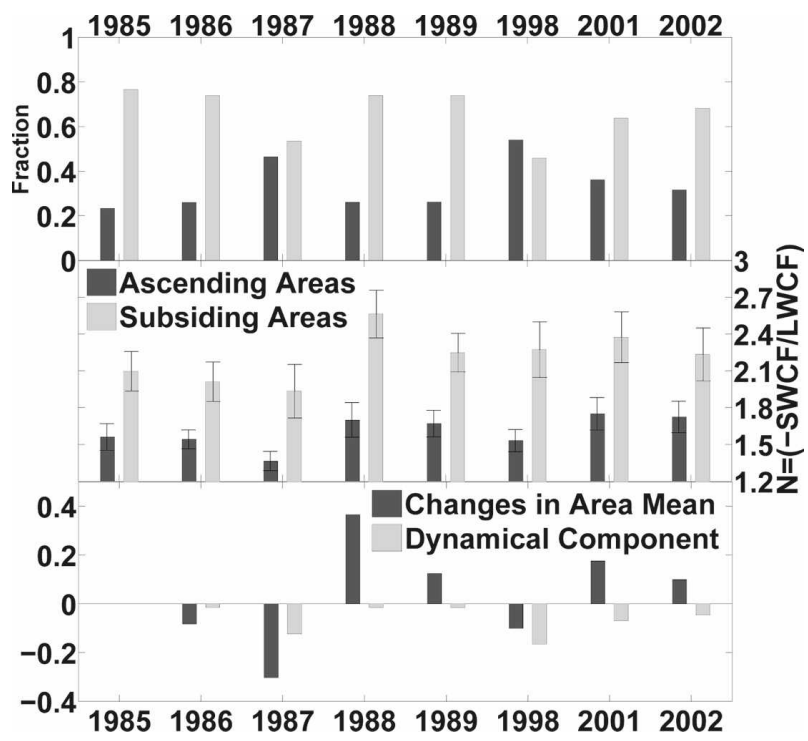

FIG. 9. Bony et al.'s (2004) analysis on $N$ in the east Pacific area based on ERA-40. (top) The fraction of the domain covered by ascending and descending motions, (middle) the values of $N$ for the ascending and descending regions, and (bottom) the changes of $N$ w.r.t. 1985 in each year. The error bars show $95 \%$ confidence limits.

served for the whole region and the change in $N$ that can be explained by the PDF of vertical velocity using the Bony et al. (2004) method. The PDF of vertical velocity, or the dynamical component, explains about one-third of the change in $N$ for 1987, and more than $100 \%$ in 1998, but a large change in $N$ occurs in 1988 with little contribution from the dynamical component. The change in $N$ between 1985 and 1988 cannot be explained by the PDF of vertical velocity.

The changes in cloud structure can be explored by using ISCCP data from the regions identified as having upward motion. Figure 10 shows significant changes in cloud structure in ascending areas that are consistent with results shown in Fig. 9. In 1987 and 1998 high, thin (low) clouds increased (decreased) significantly (95\% level) compared to 1985 in ascending areas. This is consistent with smaller values of $N$ in 1987 compared to 1985 (Fig. 9). More high, thick clouds appear in 1998, so that the $N$ value is nearly identical to 1985 . In 1988 , less high, thin clouds and more middle, thick and low clouds are present, so that $N$ is anomalously high in 1988, even though the dynamical regime is similar to 1985 .

We now turn from the east to the west Pacific region. Figure 11 is similar to Fig. 9, except for the west Pacific region chosen by Cess et al. (2001a). Although significant increases in the fractional area occupied by subsiding motion occur in 1987 and 1998, which correspond to large increases in $N$, as expected, the dynamical contribution to these changes computed by the Bony et al. 


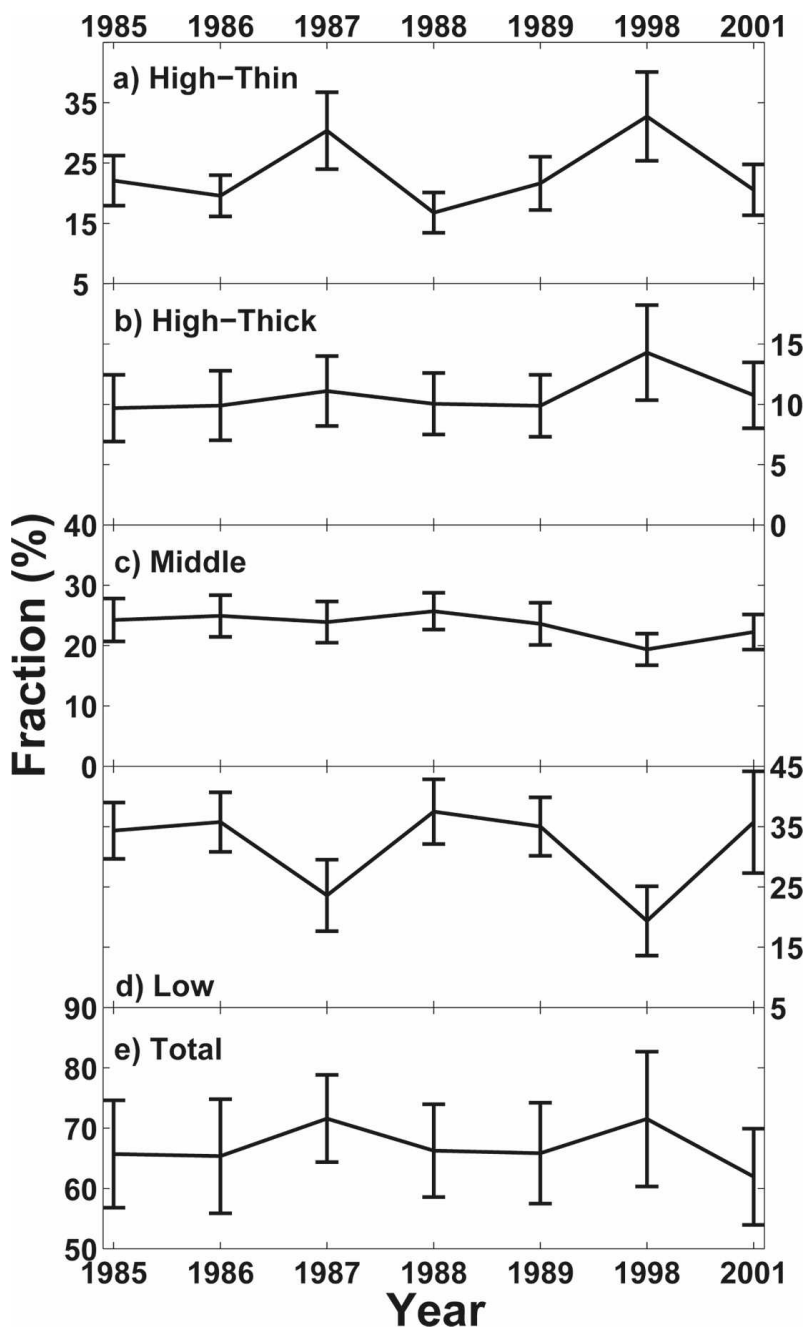

FIG. 10. ISCCP cloud structure changes in the east Pacific area.

(2004) method is small. The reasons for the small dynamical contribution can be seen in the middle panel of Fig. 11. In normal years, such as 1985 , the difference in $N$ between ascending and descending regions is small.

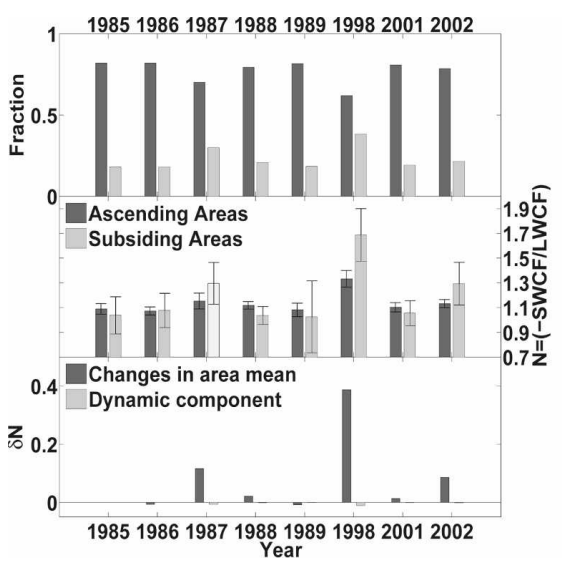

This is consistent with Fig. 2d, which shows a very weak sensitivity of $N$ to the dynamical regime in warm SST regions. If the climatological relationship between vertical velocity and $N$ is weak, then application of this relationship will not explain much of the variation of $N$. Although the fraction of subsiding motion increases from less than $20 \%$ in $1985 \%$ to $31 \%$ and $40 \%$ in 1987 and 1998, respectively, the dynamic component estimated by the Bony et al. method is small in all years.

Figure 12 shows the ISCCP data for the WP region. The fraction of high, thin cloud is anomalously low in 1998 , as is the total cloud fraction. These changes are consistent with the anomalous high value of $N$ and less LWCF observed, as shown in Fig. 11.

\section{Effects of vertical structure variations}

According to Houze (1982) convective systems (convective towers, and cloud shields associated there with) can alter the vertical structure of large-scale vertical motion by modifying the vertical profiles of heating. Back and Bretherton (2006) have shown substantial geographic variability in the vertical structure of vertical velocity in deep convective regions over the tropical Pacific Ocean. To better characterize the vertical velocity at all levels we extract the first two EOFs (EOF1 and EOF2) of the vertical velocity as a function of pressure from the monthly reanalysis data and study the first two principal components (hereafter PC1 and PC2).

Figure 13 shows EOF1 and EOF2 of the omega profiles derived from ERA-40. EOF1 shows a broad maximum between 850 and $400 \mathrm{hPa}$ and is almost equivalent to $\omega_{500}$ for representing the column mean vertical motion. The amplitude of EOF1 (PC1) is linearly correlated with $\omega_{500}$ with a correlation coefficient of 0.93 . When Bony et al.'s (2004) method is applied using PC1, similar results are obtained as for $\omega_{500}$. EOF2 represents a shifting up and down of the profile of omega.

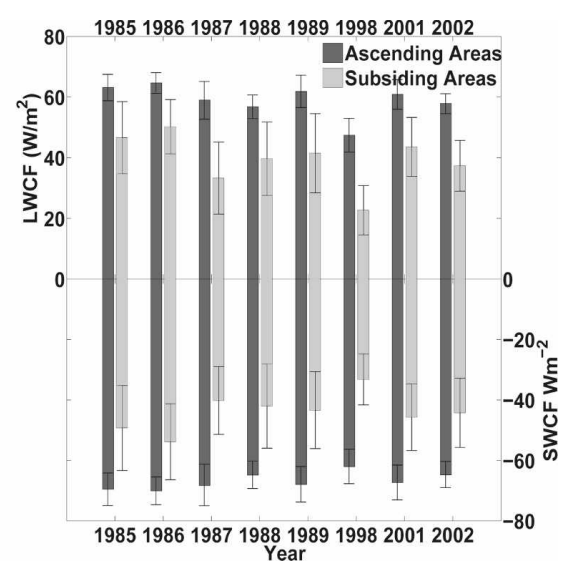

FIG. 11. Bony et al.'s (2004) analysis on $N$ in the west Pacific area based on ERA-40. 

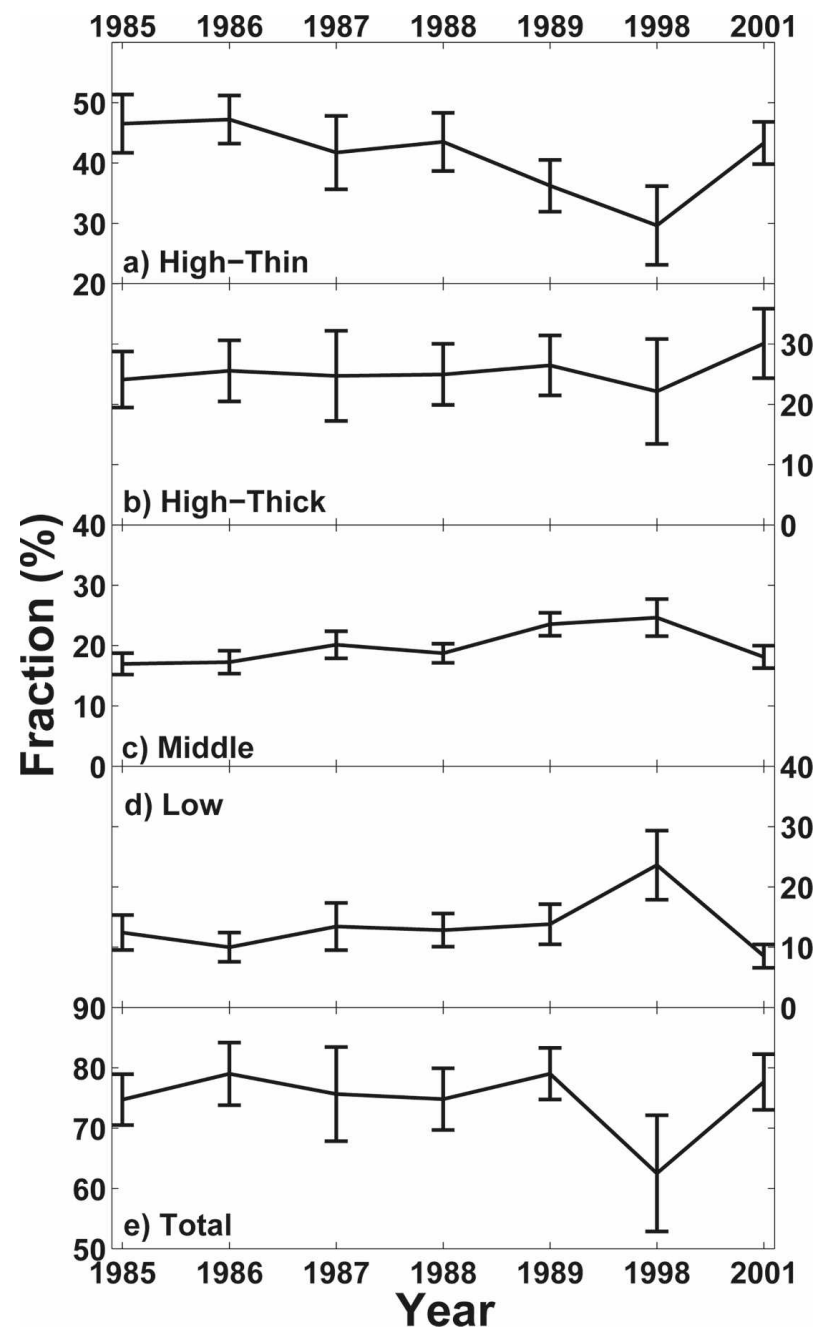

FIG. 12. ISCCP cloud structure changes in the west Pacific area.

Here we define the sign so that positive amplitude indicates enhanced upward (downward) motions at the upper (lower) troposphere, so positive PC2 represents a top-heavy upward profile. Mode one typically explains $78 \%$ of the variance of monthly means, while PC2 explains $12 \%$. These two EOFs derived from all three reanalyses are similar and statistically distinct from each other ( $95 \%$ level), after taking into account autocorrelation following Bretherton et al. (1999).

According to Cess et al. (2001c), the anomalously high $N$ in 1998 is primarily observed in the first 4 months [January-April (JFMA)] of the year. The shifts of SST and circulation patterns also primarily happened in the first 4 months of 1998. The fraction of subsiding motion during the JFMA is $37 \%$ in 1987 and $60 \%$ in 1998 , while these numbers are $26 \%$ and $20 \%$, respectively, in the later 4 months [May-August (MJJA)]. In 1998, especially during the first 4 months of the year, the warmest SST area over the west Pacific is limited to

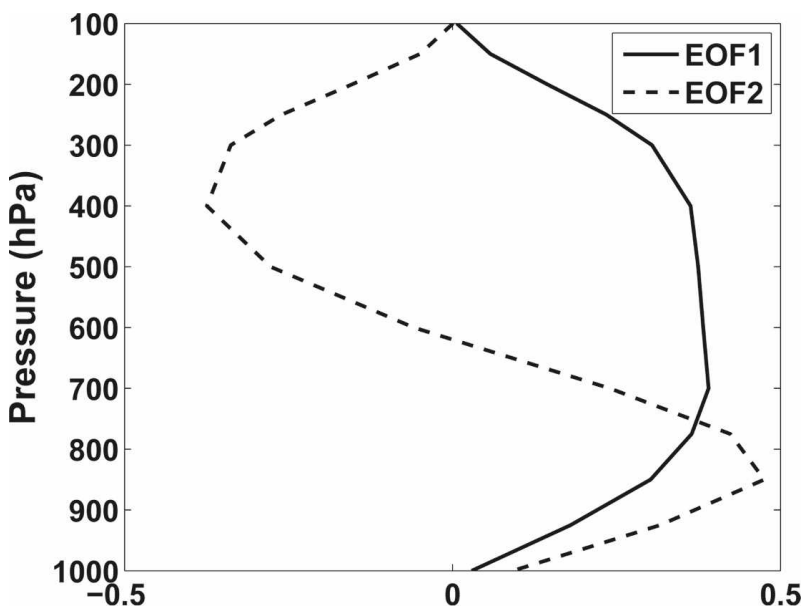

FIG. 13. First two EOFs of the vertical motion in the tropics derived from ERA-40.

a narrow band with a strong SST gradient near the equator, which is unusual for the west Pacific and more similar to the east Pacific ITCZ condition (not shown). It is interesting to see whether consistent changes occur in observed cloud properties and vertical motion profiles.

In Fig. 14 the mean of NetCRF and $N$ in the areas with rising motions are plotted against PC2. In JFMA of 1998, PC2 is significantly decreased (less "top heavy") while the NetCRF is significantly more negative (by about $15 \mathrm{~W} \mathrm{~m}^{-2}$ ). The decrease of the NetCRF is primarily due to the decrease of LWCF (see Fig. 11b). The changes in PC2 and the NetCRF in 1998 are both significant above the $95 \%$ level. Figures 11, 12, and 14 show a consistent story for the WP region during the first 4 months of 1998, in which the vertical motion profile is anomalously bottom heavy, high cloud is less abundant than normal, and the value of $N$ is larger than normal. In 2001 these conditions return to normal.

\section{Conclusions and summary}

Radiation budget quantities, such as the greenhouse effect or cloud forcing, show strong consistent relationships to the vertical velocity determined from reanalysis data products on a local basis. These relationships can be combined with changes in the PDF of vertical velocity to extract the dynamical effect, allowing other effects to be studied in greater isolation. Restricting attention to the warm-pool region with SST $>28^{\circ} \mathrm{C}$ gives somewhat different sensitivities to large-scale vertical motion than the tropical mean $\left(30^{\circ} \mathrm{N}-30^{\circ} \mathrm{S}\right)$, because the warm SST constraint removes subtropical stratocumulus regions from the analysis. The warmpool diagnostics give a linearly decreasing net cloud 

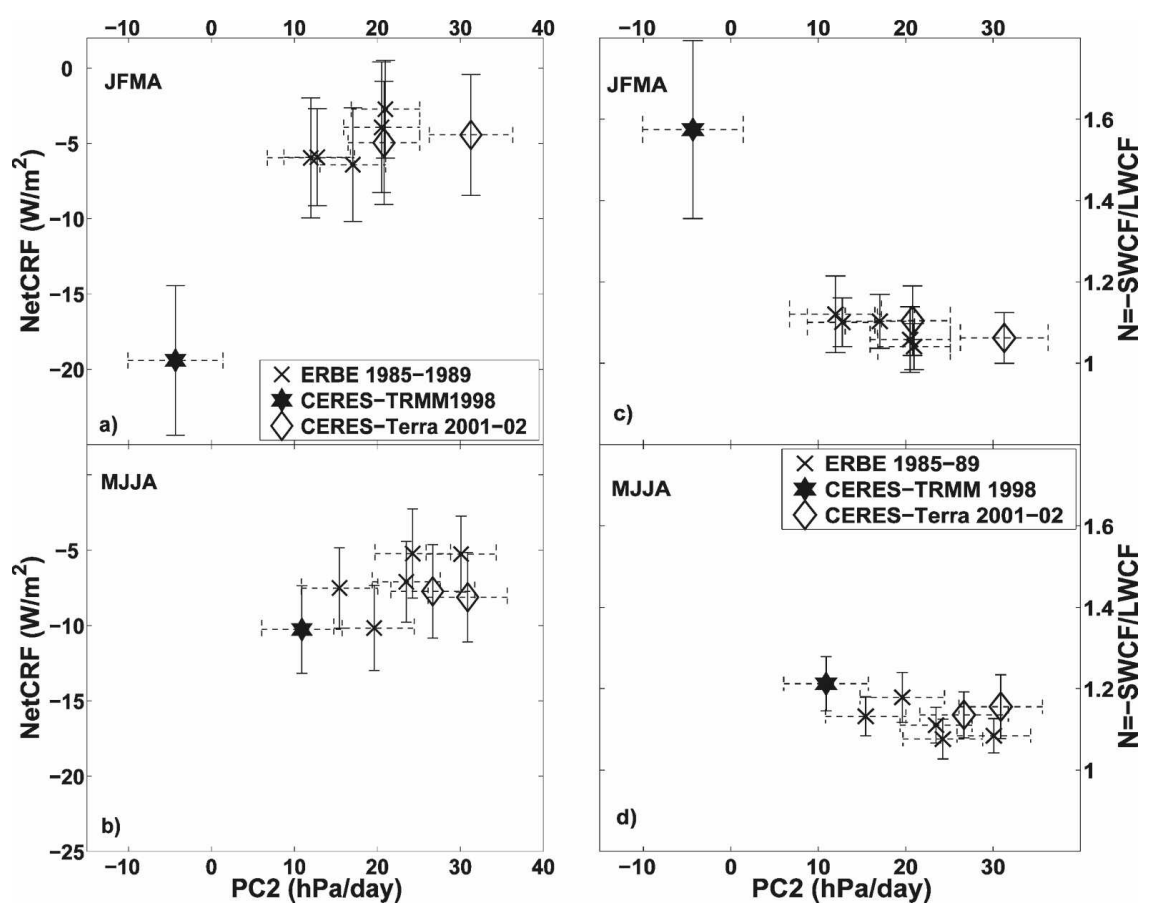

FIG. 14. NetCRF and $N$ as a function of PC2 within areas with rising motions in the west Pacific region.

radiative forcing with increasing upward vertical motion, but a very constant ratio of shortwave cloud forcing to longwave cloud forcing of about 1.2, indicating that the shortwave effect is both about $20 \%$ greater than the longwave cloud forcing and of opposite sign. A comparison of radiation budget data and ISCCP cloud data indicate that the sensitivity of net cloud radiative effect to large-scale vertical motion is mostly accounted for by the abundance of high, optically thick clouds, which have a negative impact on the TOA radiation balance, and whose abundance is well correlated with the large-scale motion field.

The annual cycles of the dynamic component of tropical mean LWCF calculated from the relationship between ERBE data and the PDF of vertical velocity are similar for each of three different reanalysis products. They show consistent and statistically significant tropical mean annual cycles with the same phase and similar amplitudes $\left(\sim 1 \mathrm{~W} \mathrm{~m}^{-2}\right)$. The dynamical component of the annual variation of tropical mean radiation budget is therefore believed to be well estimated and derived from the physical effects of the seasonal variations insolation and its interaction with continentality, SST, and insolation. The annual variation of the dynamic component is smaller than the observed annual cycle, however.

The interannual variations of dynamic components of tropical mean LWCF based on three reanalyses are well correlated with each other (correlation coefficients of 0.74 and 0.81 , significant at the $95 \%$ level), but the amplitudes are small compared to the observed variations. The dynamical component of tropical mean radiation budget quantity variations is much smaller than the observed variations for both the ERBE scanner period (1985-89) and for the longer period observed by the WFOV instruments on ERBS. Dynamic effects measured by the PDF of vertical motion appear to explain little of the variability in the ERBS WFOV data between 1985 and 1999.

In the east Pacific area discussed by Cess et al. (2001a), dynamical effect anomalies are relative large in 1987 and 1998 and seem able to explain part of the observed change in cloud forcing. Greater ascent in 1987 and 1998 contribute to smaller values of $N=$ $-\mathrm{SWCF} / \mathrm{LWCF}$, consistent with more high cloud, which is in fact observed. In 1988, the dynamical regime is similar to 1985, but the value of $N$ is larger by about 0.35. Consistently, ISCCP cloud structures in ascending areas over the east Pacific show significantly thicker clouds in 1988 than in 1985, but the explanation for this does not appear to lie in the large-scale vertical motion.

In the west Pacific Ocean region, increases of $N$ in 1987 and 1998 correspond with the greater occurrence of large-scale subsidence in the region, but the climatological difference between ascending and descending 
values of $N$ in that region do not seem to explain the observed increase in $N$, compared to the reference year of 1985. Reanalyses show significant shifts in the vertical structure of the rising motion, with upward motion less concentrated at upper levels in JFMA of 1998, consistent with strong negative NetCRF and anomalously high values of $N$. Observed changes of ISCCP cloud structures in ascending areas over the west Pacific are consistent with the structural shifts in vertical velocity seen in reanalysis. In 1998 significantly fewer high clouds and more low clouds were present. In JFMA of 1998 anomalously strong SST gradients were present near the equator in the west Pacific (not shown), and these seem to be the likely explanation for the more bottom-heavy vertical motion during that season.

It is tempting to conclude that, while useful for localized regions, shifts in large-scale dynamics cannot explain a significant fraction of the tropical mean variability in radiation budget quantities observed in the past two decades. Two issues remain to be addressed, however. The first is whether the monthly mean largescale vertical velocity fields from reanalysis are adequate for this purpose. Time and space averaging implicit in the technique as applied here could have substantial effects on the implied dynamical effect, and it is not clear that the relationships between vertical velocity and cloud properties are sufficiently linear that climatological relationships based on monthly means can capture them accurately. Related to this is the question of whether the domain-averaged PDF of vertical velocity is an adequate measure of the influence of dynamics, or if the spatial orientation of the ascending and descending motions can have a substantial impact on the radiation budget at TOA. Finally, here we have shown a significant sensitivity to the vertical structure of the large-scale circulation, which is dependent on both the spatial structure of the SST pattern (Lindzen and Nigam 1987) as well as the absolute value of the SST, where upward motion occurs (Back 2007). These questions and the related question of the ultimate cause of the observed variations in tropical mean radiation budget quantities await further study.

Acknowledgments. This work is supported by NASA Grant NNG05GA19G. The NCEP-NCAR reanalysis data are provided by the NOAA-CIRES Climate Diagnostics Center, Boulder, Colorado. ERBE scanner and ERB_WOV data were obtained from the NASA Langley Research Center EOSDIS Distributed Active Archive Center. Thanks to M. Michelsen for providing ERA-40. The authors thank C. S. Bretherton and L. Back for useful suggestions, and M. Wyant for providing ISCCP data.

\section{REFERENCES}

Allan, R. P., A. Slingo, and M. A. Ringer, 2002: Influence of dynamics on the changes in tropical cloud radiative forcing during the 1998 El Niño. J. Climate, 15, 1979-1986.

Back, L. E., 2007: Towards an improved understanding of deep convection patterns over the tropical oceans. Ph.D. thesis, University of Washington, $100 \mathrm{pp}$.

_, and C.S. Bretherton, 2006: Geographic variability in the export of moist static energy and vertical motion profiles in the tropical Pacific. Geophys. Res. Lett., 33, L17810, doi:10.1029/2006GL026672.

Barkstrom, B. R., 1984: The Earth Radiation Budget Experiment (ERBE). Bull. Amer. Meteor. Soc., 65, 1170-1185.

- and G. L. Smith, 1986: The earth radiation budget experiment: Science and implementation. Rev. Geophys., 24, 379390.

Barsugli, J. J., S. I. Shin, and P. D. Sardeshmukh, 2006: Sensitivity of global warming to the pattern of tropical ocean warming. Climate Dyn., 27, 483-492.

Bony, S., J.-L. Dufresne, H. L. Treut, J.-J. Morcrette, and C. Senior, 2004: On dynamic and thermodynamic components of cloud changes. Climate Dyn., 22, 71-86.

Bretherton, C. S., M. Widmann, V. P. Dymnikov, J. M. Wallace, and I. Blade, 1999: Effective number of degrees of freedom of a spatial field. J. Climate, 12, 1990-2009.

Cess, R. D., and Coauthors, 1996: Cloud feedback in atmospheric general circulation models. J. Geophys. Res., 101, 12 79112794.

_- M. Zhang, P. Wang, and B. A. Wielicki, 2001a: Cloud structure anomalies over the tropical Pacific during the 1997/98 El Niño. Geophys. Res. Lett., 28, 4547-4550.

,-- B. A. Wielicki, D. F. Young, X.-L. Zhou, and Y. Nikitenko, 2001b: Interpretation of cloud-climate feedback as produced by 14 atmospheric general circulation models. Science, 14, 2129-2137.

$1998,-,-\frac{\ldots}{-}$, and $-2001 \mathrm{c}$ : The influence of the 1998 El Niño upon cloud radiative forcing over the Pacific warm pool. J. Climate, 14, 2129-2137.

Chen, J. Y., B. E. Carlson, and A. D. Del Genio, 2002: Evidence for strengthening of the tropical general circulation in the 1990s. Science, 295, 838-841.

Clement, A. C., and B. Soden, 2005: The sensitivity of the tropical-mean radiation budget. J. Climate, 18, 3189-3203.

Dhuria, H. L., and H. L. Kyle, 1990: Cloud types and the tropical earth radiation budget. J. Climate, 3, 1409-1434.

Doelling, D. R., D. F. Young, B. A. Wielicki, T. Wong, and D. Keyes, 2006: The newly released 5-year Terra-based monthly CERES radiative flux and cloud product. Preprints, 12th Conf. on Atmospheric Radiation, Madison, WI, Amer. Meteor. Soc., 9.4. [Available online at http://ams.confex.com/ ams/Madison2006/techprogram/paper_112727.htm.]

Harrison, E. F., P. Minnis, B. R. Barkstrom, V. Ramanathan, R. D. Cess, and G. G. Gibson, 1990: Seasonal variation of cloud radiative forcing derived from the earth radiation budget experiment. J. Geophys. Res., 95, 18 687-18 703.

Hartmann, D. L., and M. L. Michelsen, 1993: Large-scale effects on the regulation of tropical sea surface temperature. J. Climate, 6, 2049-2062. 
_ M. E. Ockert-Bell, and M. L. Michelsen, 1992: The effect of cloud type on earth's energy balance: Global analysis. J. Climate, 5, 1281-1304.

- L. A. Moy, and Q. Fu, 2001: Tropical convection and the energy balance at the top of the atmosphere. J. Climate, 14, 4495-4511.

Houze, R. A., Jr., 1982: Cloud clusters and large-scale vertical motions in the tropics. J. Meteor. Soc. Japan, 60, 396-410.

Kalnay, E., and Coauthors, 1996: The NCEP/NCAR 40-Year Reanalysis Project. Bull. Amer. Meteor. Soc., 77, 437-471.

Kanamitsu, M., W. Ebisuzaki, J. Woollen, S.-K. Yang, J. J. Hnilo, M. Fiorino, and G. L. Potter, 2002: NCEP-DOE AMIP-II Reanalysis (R-2). Bull. Amer. Meteor. Soc., 83, 1631-1643.

Kiehl, J. T., 1994: On the observed near cancellation between longwave and shortwave cloud forcing in tropical regions. J. Climate, 7, 559-565.

- , and V. Ramanathan, 1990: Comparison of cloud forcing derived from the Earth Radiation Budget Experiment with that simulated by the NCAR Community Climate Model. J. Geophys. Res., 95, 11 679-11 698.

Kistler, R., and Coauthors, 2001: The NCEP-NCAR 50-Year Reanalysis: Monthly means CD-ROM and documentation. Bull. Amer. Meteor. Soc., 82, 247-267.

Klein, S. A., and D. L. Hartmann, 1993: The seasonal cycle of low stratiform clouds. J. Climate, 6, 1587-1606.

Kubar, T. L., D. L. Hartmann, and R. Wood, 2007: Radiative and convective driving of tropical high clouds. J. Climate, 20, $5510-5526$.

Larson, K., and D. L. Hartmann, 2003: Interactions among cloud, water vapor, radiation and large-scale circulation in the tropical climate. Part I: Sensitivity to uniform sea surface temperature changes. J. Climate, 16, 1425-1440.

Lindzen, R. S., and S. Nigam, 1987: On the role of sea surface temperature gradients in forcing low-level winds and convergence in the tropics. J. Atmos. Sci., 44, 2418-2436.

- M. D. Chou, and A. Y. Hou, 2001: Does the earth have an adaptative infrared iris? Bull. Amer. Meteor. Soc., 82, 417432.

Lu, R., B. Dong, R. D. Cess, and G. L. Potter, 2004: The 1997/98 El Nino: A test for climate models. Geophys. Res. Lett., 31, L12216, doi:10.1029/2004GL019956.

Ockert-Bell, M. E., and D. L. Hartmann, 1992: The effect of cloud type on Earth's energy balance: Results for selected regions. J. Climate, 5, 1157-1171.
Ramanathan, V., and W. Collins, 1991: Thermodynamic regulation of ocean warming by cirrus clouds deduced from observations of the 1987 El Niño. Nature, 351, 27-32.

- R. D. Cess, E. F. Harrison, P. Minnis, B. R. Barkstrom, E. Ahmad, and D. L. Hartmann, 1989: Cloud-radiative forcing and climate: Results from the earth radiation budget experiment. Science, 243, 57-63.

Rossow, W. B., and R. Schiffer, 1999: Advances in understanding clouds from ISCCP. Bull. Amer. Meteor. Soc., 80, 2261-2288.

Schneider, S. H., 1972: Cloudiness as a global climatic feedback mechanism: The effects on the radiation balance and surface temperature of variations in cloudiness. J. Atmos. Sci., 29, $1413-1422$.

Smith, T. M., and R. W. Reynolds, 2004: Improved extended reconstruction of SST (1854-1997). J. Climate, 17, 2466-2477.

Solomon, S., D. Qin, M. Manning, M. Marquis, K. Averyt, M. M. B. Tignor, H. L. Miller Jr., and Z. Chen, 2007: Climate Change 2007: The Physical Science Basis. Cambridge University Press, $800 \mathrm{pp}$.

Stephens, G. L., 2005: Cloud feedbacks in the climate system: A critical review. J. Climate, 18, 237-273.

Taylor, V. R., and L. L. Stowe, 1984: Reflectance characteristics of uniform earth and cloud surface derived from Nimbus-7 ERB. J. Geophys. Res., 89, 4987-4996.

Uppala, S., and Coauthors, 2005: The ERA-40 Re-Analysis. Quart. J. Roy. Meteor. Soc., 131, 2961-3012.

Wielicki, B., B. Barkstrom, E. Harrison, R. B. Lee III, G. L. Smith, and J. E. Cooper, 1996: Clouds and the Earth's Radiant Energy System (CERES): An Earth Observing System experiment. Bull. Amer. Meteor. Soc., 77, 853-868.

— , and Coauthors, 2002: Evidence for large decadal variability in the tropical mean radiative energy budget. Science, 295, 841-844.

Wong, T., B. A. Wielicki, I. Robert, B. Lee, G. L. Smith, and K. A. Bush, 2006: Reexamination of the observed decadal variability of the earth radiation budget using altitudecorrected ERBE/ERBS nonscanner WFOV data. J. Climate, 19, 4028-4040.

Zhang, Y. C., W. B. Rossow, A. A. Lacis, V. Oinas, and M. I. Mishchenko, 2004: Calculation of radiative fluxes from the surface to top of atmosphere based on ISCCP and other global data sets: Refinements of the radiative transfer model and the input data. J. Geophys. Res., 109, D19105, doi:10.1029/ 2003 JD004457. 
Copyright of Journal of Climate is the property of American Meteorological Society and its content may not be copied or emailed to multiple sites or posted to a listserv without the copyright holder's express written permission. However, users may print, download, or email articles for individual use. 